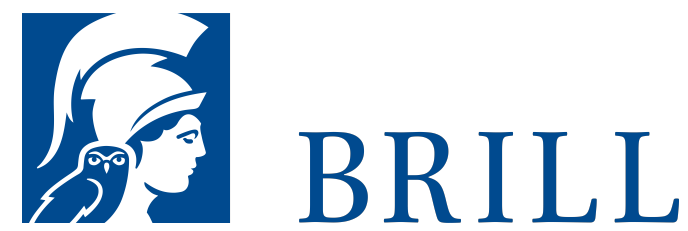

\title{
Volksschule und Elementarbildung
}

\section{Author: Wilhelm Flitner}

Die Grundlegung einer Elementarbildung, die als gemeinsame Volksbildung noch in die Erwachsenenbildung hineinreicht und auch in der Gymnasialbildung wirksam bleibt, war eines der Lebensthemen Wilhelm Flitners (1889-199o), der wohl zu den bedeutendsten deutschen PÃødagogen des 20.Jh. zÃ̋hlen darf.

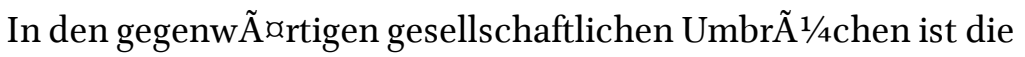
Frage, wie die Schule zu einer solchen allgemeinen Bildung beitragen kann, erneut virulent geworden. Band 9 der Werkausgabe enthÃalt die Schriften zur Volksschule, also der heutigen Grund- und Hauptschule. Im Zentrum: die von 1941 bis 1966 stã andig neu bearbeitete Schrift â€žDie vier Quellen des Volksschulgedankensâ€œ. Hier fordert Flitner durch eine systematische historische Darstellung zur Auseinandersetzung mit fortbestehenden und neuen Problemen einer durch Schule getragenen Bildung geradezu heraus. Dabei zeigt der Band anhand der einzelnen Bearbeitungen die VerÃannderungen von Flitners Problemhorizont. Vor allem sind bislang unverÃ $\llbracket$ ffentlichte Typoskripte aus dem NachlaÃŸ aufgenommen worden: St $\tilde{A}^{1} / 4$ cke eines Ende der 6oer Jahre begonnenen zweiten, â€žpragmatischenâ€œ Teils, in dem Flitner die bislang von der Volksschule wahrgenommenen Aufgaben neu bestimmen und ihren Platz im sich verÃanderndem Schulsystem zeigen will. â€žDas Erscheinen des wissenschaftlichen Gesamtwerks von Wilhelm Flitner ist ein besonderes Ereignis der erziehungswissenschaftlichen Publizistik.â€œ 
Please send your order to: Brockhaus/Commission Tel: +49(o)71 541327 9216 | E-Mail: brill@ $\underline{\text { brocom.de }}$

For questions please contact: Brill Deutschland GmbH

Wollmarktstraße 115 | 33098 Paderborn | Germany

Tel: +49 (o)5251 69975 o | E-Mail: sales@brill.com. 